\title{
Trends in Prevalent and Incident Opioid Receipt: an Observational Study in Veterans Health Administration 2004-2012
}

\author{
H. J. Mosher, MFA, M.D. ${ }^{1,2,8}$, E. E. Krebs, M.D., M.P.H. ${ }^{3}$, M. Carrel, Ph.D. ${ }^{1,4}$, P. J. Kaboli, M.D., M.S. ${ }^{1,2,5}$, \\ M. W. Vander Weg, Ph.D. ${ }^{1,2,6}$, and B.C. Lund, Pharm.D. ${ }^{1,7}$
}

'Center for Comprehensive Access and Delivery Research and Evaluation (CADRE), lowa City VA Healthcare System, lowa City, IA, USA; ${ }^{2}$ Department of Internal Medicine, University of lowa Carver College of Medicine, lowa City, IA, USA; ${ }^{3}$ Center for Chronic Disease Outcomes Research, Minneapolis VA Health Care System and University of Minnesota Medical School, Minneapolis, MN, USA; ${ }^{4}$ Department of Geographical \& Sustainability Sciences, University of lowa, lowa City, IA, USA; ${ }^{5}$ lowa VA Office of Rural Health (ORH), Veterans Rural Health Resource CenterCentral Region, lowa City VA Healthcare System, lowa City, IA, USA; ${ }^{6}$ Department of Psychology, University of lowa, lowa City, IA, USA; ${ }^{7}$ Department of Epidemiology, University of lowa College of Public Health, lowa City, IA, USA; ${ }^{8}$ lowa City VA Healthcare System, lowa City, IA, USA.

BACKGROUND: Improved understanding of temporal and regional trends may support safe and effective prescribing of opioids.

OBJECTIVE: We describe national, regional, and facilitylevel trends and variations in opioid receipt between fiscal years (FY) 2004 and 2012.

DESIGN: Observational cohort study using Veterans Health Administration (VHA) administrative databases.

PARTICIPANTS: All patients receiving primary care within 137 VHA healthcare systems during a given study year and receiving medications from VHA one year before and during a given study year.

MAIN MEASURES: Prevalent and incident opioid receipt during each year of the study period.

KEY RESULTS: The overall prevalence of opioid receipt increased from $18.9 \%$ of all veteran outpatients in FY2004 to $33.4 \%$ in $\mathrm{FY} 2012$, a $76.7 \%$ relative increase. In FY2012, women had higher rates of prevalent opioid receipt than men (42.4\% vs. $32.9 \%$ ), and the youngest veterans (18-34 years) had higher prevalent opioid receipt compared to the oldest veterans ( $\geq 80$ years) ( $47.6 \%$ vs. $17.9 \%)$. All regions in the United States saw increased rates of prevalent opioid receipt during this time period. Prevalence rates varied widely by facility: in FY2012, the lowest-prescribing facility had a rate of $13.5 \%$, and the highest of $50.8 \%$. Annual incident opioid receipt increased from $8.8 \%$ in FY2004 to $10.2 \%$ in FY2011, with a decline to $9.8 \%$ in FY2012. Incident prescribing increased at some facilities and decreased at others. Facilities with high prevalent prescribing tended to have flat or decreasing incident prescribing rates during the study time frame.

CONCLUSIONS: Rates of opioid receipt increased throughout the study time frame, with wide variation in prevalent and incident rates across geographical region, sex, and age groups. Prevalence and incidence rates reflect distinct prescribing practices. Areas with the highest prevalence tended to have lower increases in incident opioid receipt over the study period. This likely reflects facilitylevel variations in prescribing practices as well as baseline rates of prevalent use. Future work assessing opioid

Received June 3, 2014

Revised October 10, 2014

Accepted November 24, 2014

Published online December 18, 2014 prescribing should employ methodologies to account for and interpret both prevalent and incident opioid receipt.

KEY WORDS: opioids; prevalence; incidence; veterans.

J Gen Intern Med 30(5):597-604

DOI: $10.1007 / \mathrm{s} 11606-014-3143-z$

(C) Society of General Internal Medicine 2014

\section{BACKGROUND/INTRODUCTION}

Increasing rates of opioid analgesic use and opioid-related deaths are well-documented and highly publicized. ${ }^{1-6}$ Increased use is variously quantified as number of opioid prescriptions, ${ }^{7}$ percentage of primary care visits resulting in opioid prescription, ${ }^{8-10}$ opioid sales in milligrams per 10,000 capita, ${ }^{11}$ and average dose of medication per health plan participant. ${ }^{12}$ However, these data can be difficult to interpret. For example, changes in total volume of opioids prescribed could be attributed to escalating doses, changes in potency or formulation, or longer duration of use, without necessarily involving a greater number of individuals receiving opioids. Thus it remains uncertain whether the increasing opioid consumption nationally is due to more widespread use or more intensive use by a relatively fixed number of individuals.

One potential driver of the increasing prevalence of opioid receipt is greater incidence. Incident recipients of opioids are the subset of prevalent recipients for whom opioids are newly prescribed. Incidence may better reflect current prescribing attitudes, and it may be easier to reduce rates of new prescribing than to modify existing drug regimens. Prevalence blurs current practices with past practices, ${ }^{13}$ and thus a comparison of changes in prevalent and incident opioid receipt helps to clarify increased use. To date, opioid incidence and prevalence have not been compared in a comprehensive cohort.

While opioids may be appropriate for acute pain, the safety and effectiveness of long-term use remain unproven. Differentiating incident use from recurrent or persistent use is clinically meaningful when describing trends and patterns. Opioid use nationally appears to be increasing contemporaneously with a heightened public awareness of opioid risks and greater 
questioning of the appropriateness of long-term prescribing. ${ }^{14,15}$ Among patients who are prescribed opioids, the average days' supply appears to be increasing. ${ }^{3}$

To understand the prescribing patterns driving increased opioid use, we retrospectively assessed trends in prevalent and incident opioid receipt over time, stratified by patient geographical location, age, and sex. Our secondary objective, to compare trends in prevalent and incident use by facility, tested the hypothesis that despite national increases rates of opioid prescribing were stable or even decreasing at individual facilities. Geographical variation and temporal fluctuation in prevalent and incident receipt reflect informative differences, and identifying these differences will inform future study of high, low, or rapidly changing facilities to yield insights into facilitators and barriers to optimal opioid prescribing.

\section{METHODS}

\section{Data Sources}

This retrospective observational cohort study utilized national administrative VHA datasets for FY2003 through FY2012 from the Austin Information Technology Center (Austin, TX, USA). Outpatient Medical SAS datasets were used to identify primary care visits, and prescription drug records were obtained from the Decision Support System National Data Extracts. The date of service for prescription drugs in this data source is the date dispensed. Records from these sources were linked using a scrambled patient identification number.

\section{Patients}

The target population included all veterans receiving outpatient primary care services and medications from VHA. Patient cohorts were created individually for each year from FY2004 through FY2012. Patients were included if they had at least one outpatient VHA primary care visit during the target year and had evidence of regular VHA medication use during both the target year and the preceding year. Regular medication use was defined as any outpatient prescription fills that spanned at least 240 calendar days during the year. ${ }^{16,17}$ Regular medication use during the preceding year was required in order to allow for the identification of incident opioid receipt during the target year.

\section{Opioid Receipt}

Opioid receipt was restricted to all outpatient prescription fills of a non-injectable dosage form, regardless of quantity or days' supply, for any of the following medications: butorphanol, fentanyl, hydrocodone, hydromorphone, levorphanol, meperidine, methadone, morphine, oxycodone, oxymorphone, pentazocine, and tramadol. Opioids administered during an inpatient hospital admission were excluded. Tramadol was included, as it is has addiction and abuse potential. ${ }^{18,19}$ Codeine was excluded, as it may be prescribed for non-pain conditions. Prevalent opioid receipt during a given year was defined as the receipt of at least one opioid prescription during that year. Incident opioid receipt, a subset of prevalent receipt, was defined as the presence of a first opioid prescription during a given fiscal year, preceded by a one-year (365 day) period with no opioid prescribed. ${ }^{20}$

\section{Analysis}

Annual prevalence and incidence rates of prescription opioid receipt were determined in aggregate for FY2004 through FY2012, and stratified based on sex and age. To supplement crude stratified frequencies, multivariable logistic regression was used to determine the independent contributions of sex and age on the likelihood of opioid receipt. In three sensitivity analyses, we examined the stability of the main findings based on alternative patient selection criteria and opioid definitions. To assist in the interpretation of the relative changes in prevalence and incidence over time, we added a post hoc analysis measuring the number of estimated calendar days of presumed use for prevalent opioid recipients during FY2004 and FY2012. All analyses were conducted using SAS version 9.3 (Cary, NC. USA).

Each patient was assigned to one of 137 VHA healthcare systems, including affiliated outpatient clinics, based on where the patient had received the majority of primary care during the study year of interest. Facility-level relationships between prevalence and incidence, as well as change in incidence during the observation period, were reported using the nonparametric Spearman correlation coefficient. To examine the relationship between facility-level trends in prevalent and incident prescribing, facilities were grouped based on change in incident prescribing over the study period.

Catchment area maps for medical centers were created to depict the national variation in percentage of veterans receiving an opioid prescription across VHA medical centers. Medical centers were grouped into geographical regions based on approximate overlap with U.S. Census regions. ${ }^{21}$ Catchment areas for each medical center were based on county-level use of VHA primary care services. Each county was assigned a single medical center based on where the greatest number of its veteran residents received primary care. Counties were then aggregated into catchment areas based on shared VHA medical centers providing the majority of care to county veteran residents. These catchment areas were used solely for the geographical representation of opioid receipt. National opioid receipt rate maps were created using ArcGIS to indicate variation in prescribing patterns across the U.S. (v. 10.1, Esri, Redlands, CA, USA). The authors had full access to and take full responsibility for the integrity of the data. The study was approved by the University of Iowa Institutional Review Board and the Iowa City VA Healthcare System Research and Development Committee.

\section{RESULTS}

The baseline study population (FY2004) included 2,239,752 patients, of whom 91,011 (4.1\%) were women and 2,148,741 
(95.9 \%) were men. In FY2012, the total cohort included 2,740,618 patients, of which 152,519 (5.6\%) were women. Age distributions are reported in Table 1.

\section{National Trends in Prevalent and Incident Opioid Receipt}

The prevalence of opioid receipt increased each year between FY2004 and FY2012, with an overall change from $18.9 \%$ of all patients to $33.4 \%$ of all patients, a $76.7 \%$ relative increase (Fig. 1). Prevalent receipt was highest in the 18-34 and 35-49 age groups, and increased over time across all age categories (Table 1). By FY2012, nearly half of all patients in these two age groups had been prescribed an opioid within the preceding 12 months. Veterans age 65 years and older were less likely than younger veterans to be prescribed opioids, although between FY2004 and FY2012, this difference narrowed for the 65-79 age group. Simultaneously, the odds ratio for prevalent receipt among the oldest old $(\geq 80)$ declined. Women received opioids at higher rates than men in all years considered.

Incident opioid receipt rates were highest among younger age groups. While incidence of opioid receipt increased nationally from $8.7 \%$ in FY2004 to $9.6 \%$ in FY2012, this increase was driven entirely by increases among those $65-79$ years of age (Table 1).

\section{Geographical Variation in Prevalent Opioid Receipt}

The prevalence of opioid receipt varied by region during all study years. Regions with higher versus lower receipt rates were consistent across the time period; the pattern observed for
FY2012 (Fig. 2) is representative. In FY2012, the mean percentage of veterans who received opioids, aggregated at the facility level, was $33.0 \%(\mathrm{SD}=8.2)$; the percentage in the Northeast was $23.4 \%(\mathrm{SD}=5.3)$, the Midwest $30.9 \%(\mathrm{SD}=$ 6.2), the South $38.7 \%$ ( $\mathrm{SD}=6.0$ ), and the West $37.2 \%$. Within regions, there was also substantial facility-level variation in opioid receipt. In FY2012, the lowest-prescribing facility had a rate of $13.5 \%$, and the highest of $50.8 \%$.

\section{Geographical Variation in Incident Opioid Receipt}

Rates of incident opioid receipt were highest in the West and South during each year of the study period. In FY2012, the mean facility-level rate of incident prescribing nationally was $9.5 \%(\mathrm{SD}=1.8)$; in the Northeast this was $7.9 \%(\mathrm{SD}=1.6)$, the Midwest $9.0 \%(\mathrm{SD}=1.3)$, the South $10.5 \%(\mathrm{SD}=1.3)$, and in the West $10.3 \%(\mathrm{SD}=1.7)$. Facility-level incident prescribing rates ranged between $4.2 \%$ and $13.3 \%$ (Fig. 2).

\section{Relationship Between Facility-Level Trends in Prevalent and Incident Opioid Prescribing}

Facilities were grouped by absolute change in incident prescribing over the study period ( $>0.5 \%$ decrease, no change, $0.5-1.5$ $\%$ increase, $\geq 1.5 \%$ increase). Changes in prevalent prescribing were then compared across these groupings (Table 2). The facility group experiencing the largest decreases in incidence ( $>0.5 \%$ decrease) had a prevalence of $25.4 \%$ in FY2004 and a prevalence of $39.3 \%$ in FY2012, a $13.9 \%$ absolute increase. The facility group with the largest increases in incidence had a prevalence of $12.8 \%$ in FY2004, and a prevalence of $27.4 \%$ in

Table 1 Prevalent and Incident Opioid Receipt in VHA, Stratified by Sex and Age

\begin{tabular}{|c|c|c|c|c|}
\hline \multirow[b]{2}{*}{ Variable } & \multicolumn{2}{|l|}{ FY04 } & \multicolumn{2}{|l|}{ FY12 } \\
\hline & $\begin{array}{l}\text { Frequency } \\
\text { n / N (\%) }\end{array}$ & $\begin{array}{l}\text { Adjusted } \\
\text { OR }(95 \% \text { CI })^{1}\end{array}$ & $\begin{array}{l}\text { Frequency } \\
\text { n / N (\%) }\end{array}$ & $\begin{array}{l}\text { Adjusted } \\
\text { OR }(95 \% \text { CI) }\end{array}$ \\
\hline \multicolumn{5}{|c|}{ Opioid Prevalent Receipt } \\
\hline All Patients & $422,344 / 2,239,752(18.9)$ & - & $916,504 / 2,740,618(33.4)$ & - \\
\hline $\begin{array}{l}\text { Sex } \\
\text { Women }\end{array}$ & $24,877 / 91,011(27.3)$ & $1.12(1.10,1.14)$ & $64,712 / 152,519(42.4)$ & $1.06(1.04,1.07)$ \\
\hline Men & $397,467 / 2,148,741(18.5)$ & Reference & $851,792 / 2,588,099(32.9)$ & Reference \\
\hline \multicolumn{5}{|l|}{ Age, years } \\
\hline $18-34$ & $5,382 / 17,498(30.8)$ & $1.19(1.16,1.23)$ & $24,008 / 50,452(47.6)$ & $1.19(1.17,1.21)$ \\
\hline $35-49$ & $57,861 / 167,887(34.5)$ & $1.44(1.42,1.46)$ & $97,617 / 205,950(47.4)$ & $1.19(1.18,1.20)$ \\
\hline $50-64$ & $185,117 / 699,329(26.5)$ & Reference & $451,006 / 1,049,006(43.0)$ & Reference \\
\hline $65-79$ & $136,097 / 1,033,323(13.2)$ & $0.42(0.42,0.43)$ & $262,184 / 979,242(26.8)$ & $0.49(0.48,0.49)$ \\
\hline$\geq 80$ & $37,887 / 321,703(11.8)$ & $0.37(0.37,0.38)$ & $81,689 / 455,967$ (17.9) & $0.29(0.29,0.29)$ \\
\hline \multicolumn{5}{|c|}{ Opioid Incident Receipt } \\
\hline All Patients & $197,201 / 2,239,752(8.8)$ & - & $267,288 / 2,740,618(9.8)$ & - \\
\hline \multicolumn{5}{|l|}{ Sex } \\
\hline Women & 11,086/91,011 (12.2) & $1.20(1.18,1.23)$ & $18,600 / 152,519(12.2)$ & $1.14(1.12,1.16)$ \\
\hline Men & $186,115 / 2,148,741(8.7)$ & Reference & $248,688 / 2,588,099(9.6)$ & Reference \\
\hline \multicolumn{5}{|l|}{ Age, years } \\
\hline $18-34$ & 2,074/17,498 (11.9) & $0.98(0.93,1.03)$ & $5,888 / 50,452(11.7)$ & $1.00(0.97,1.03)$ \\
\hline $35-49$ & $21,047 / 167,887(12.5)$ & $1.08(1.06,1.09)$ & $24,622 / 205,950(12.0)$ & $1.04(1.02,1.05)$ \\
\hline $50-64$ & $80,484 / 699,329(11.5)$ & Reference & $119,616 / 1,049,006$ (11.4) & Reference \\
\hline $65-79$ & 72,706/1,033,323 (7.0) & $0.59(0.58,0.59)$ & $87,251 / 979,242(8.9)$ & $0.77(0.76,0.77)$ \\
\hline$\geq 80$ & $20,890 / 321,703(6.5)$ & $0.54(0.53,0.54)$ & $29,911 / 455,967$ (6.6) & $0.55(0.54,0.56)$ \\
\hline
\end{tabular}

$F Y=$ Fiscal Year

${ }^{I}$ Odds ratios (OR) determined by multiple logistic regression, with sex and age groups as independent variables 


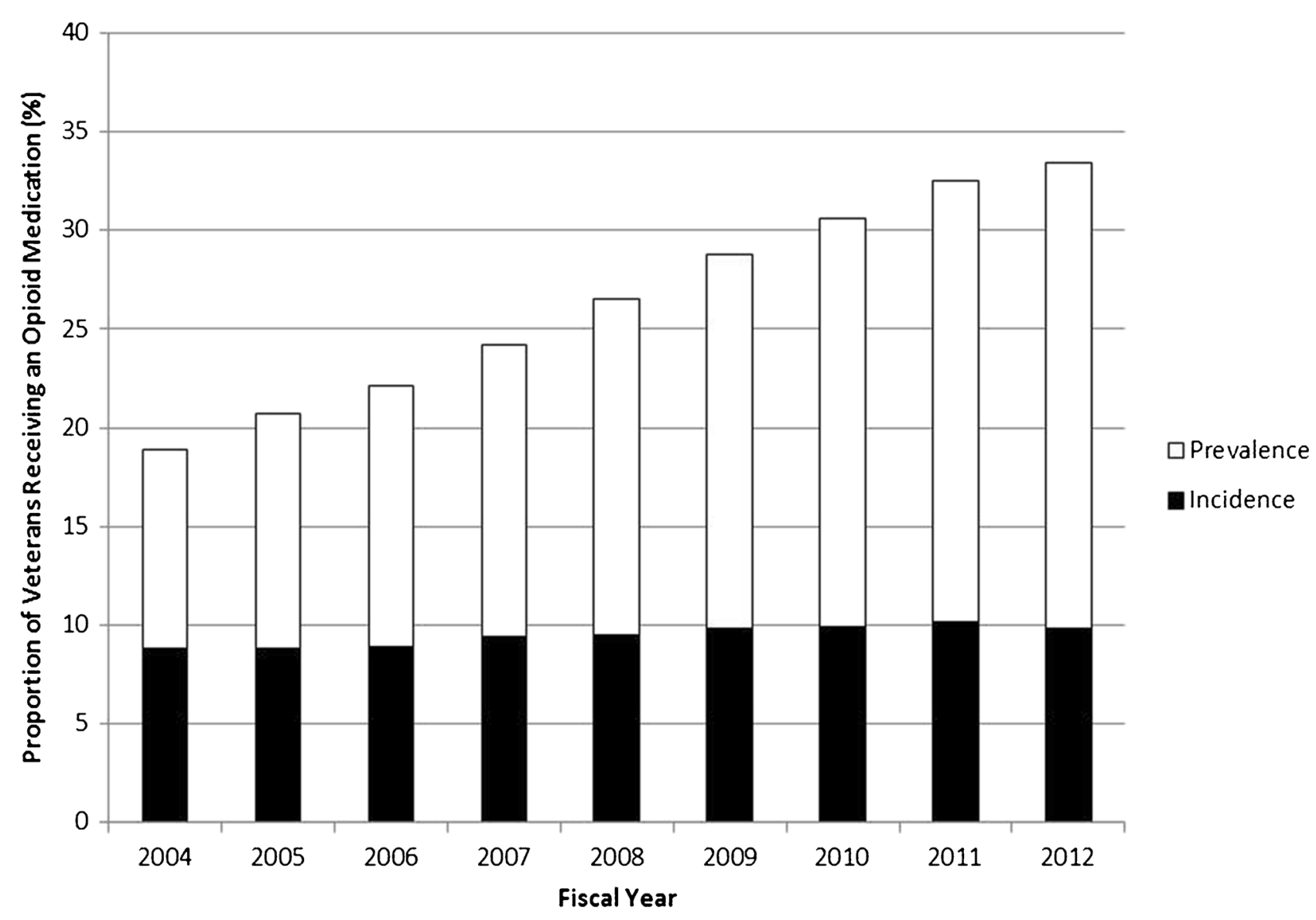

Figure 1 Prevalence and Incidence of Opioid Prescribing from FY2004 to FY2012 in Veterans Health Administration

FY2012, a $14.6 \%$ absolute increase. Absolute increases in prevalence between FY2004 and FY2012 were largely unrelated to incidence groupings.

As a complement to this categorical approach, we examined facility-level correlations between opioid prevalent and incident prescribing. Within a given year, prevalence and incidence rates were positively correlated (Spearman correlation, FY2004: 0.913, p <0.001; FY2012: $0.654, \mathrm{p}<0.001)$. However, the change in incident prescribing from FY2004 to FY2012 was negatively correlated with FY2004 prevalent prescribing rates (Spearman correlation: $-0.755 ; \mathrm{p}<0.001$ ) and with FY2004 incident prescribing rates (Spearman correlation: $-0.730 ; p<0.001)$. In other words, the greatest increases in opioid incident prescribing were seen in facilities that began with the lowest FY2004 prevalence and incidence rates.

\section{Supplemental Analyses}

Two sensitivity analyses examined alternative opioid classifications. Specifically, we wanted to assess our decisions to include tramadol and exclude codeine. Excluding tramadol resulted in lower prevalent and incident prescribing rates but similar relative changes over time, as in the main findings.
Conversely, including codeine resulted in increased prevalence and incidence rates. The relative change in prevalence was similar to the main findings.

A third sensitivity analysis determined the extent to which opioid prevalent and incident receipt rates were affected by applying alternative patient selection criteria, omitting the requirement for regular use of VHA medications and only requiring at least one primary care visit. Opioid receipt prevalence rates in this less restrictive patient population were 15.4 \% in FY2004 and $25.4 \%$ in FY2012, which are lower in absolute value than the main study findings ( $18.9 \%$ and 33.4 $\%$, respectively), but reflect a similar relative change over time. Opioid incidence rates in this sensitivity analysis were $8.7 \%$ in FY2004 and $10.0 \%$ in FY2012, which are nearly identical to the main findings ( $8.8 \%$ and $9.8 \%$, respectively).

The observation of increasing prevalent receipt that outpaced changes in incident receipt suggests that the cumulative duration of opioid use is increasing. Therefore, we also added a post hoc analysis examining the average number of calendar days of presumed use for veterans receiving opioids during FY2004 and FY2012. The median number of calendar days of presumed opioid use during FY2004 was 87 days (interquartile range: $30-246$ days), and increased to 147 days (interquartile range: 30-299 days) in FY2012. 


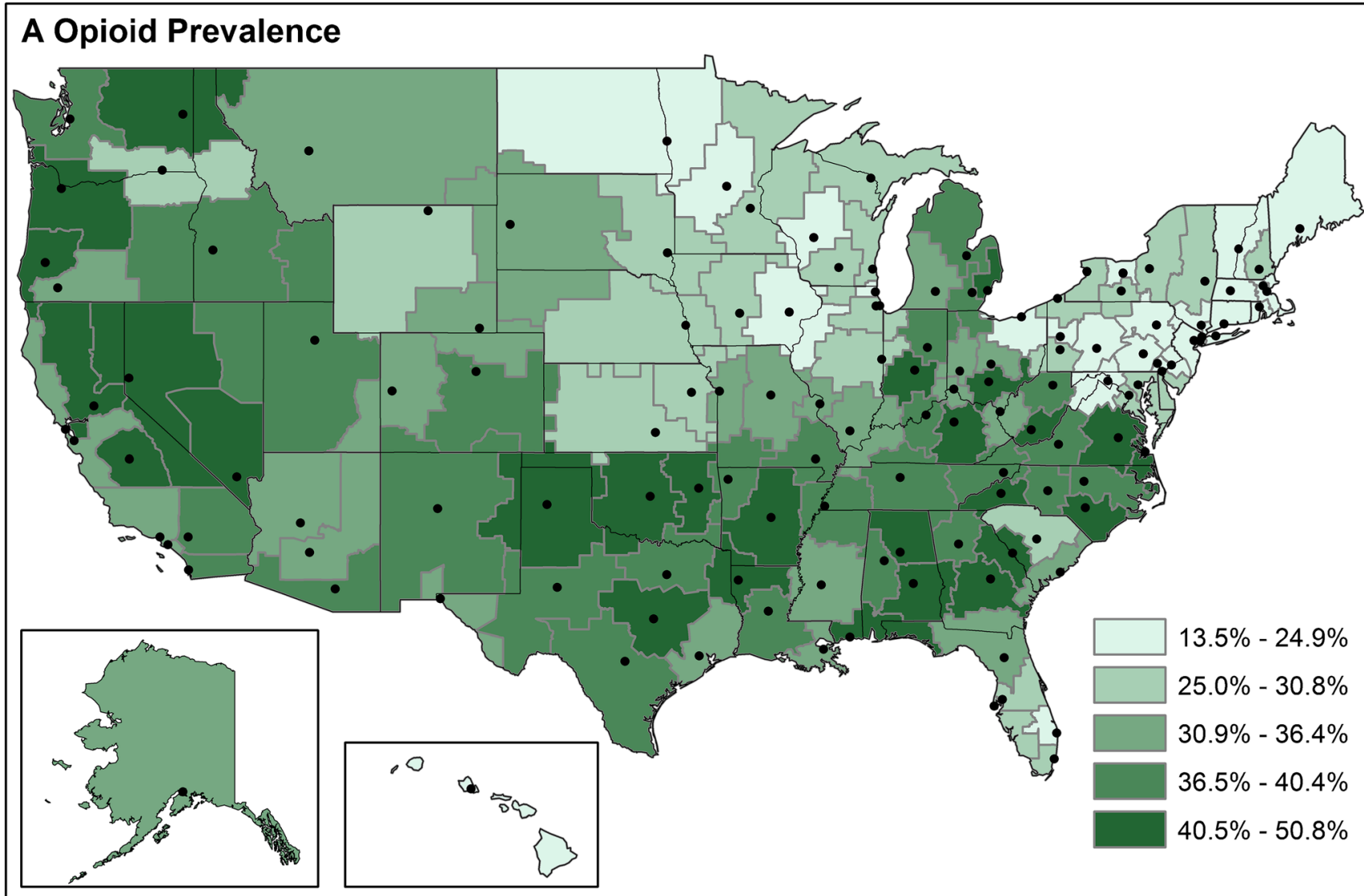

\section{B Opioid Incidence}

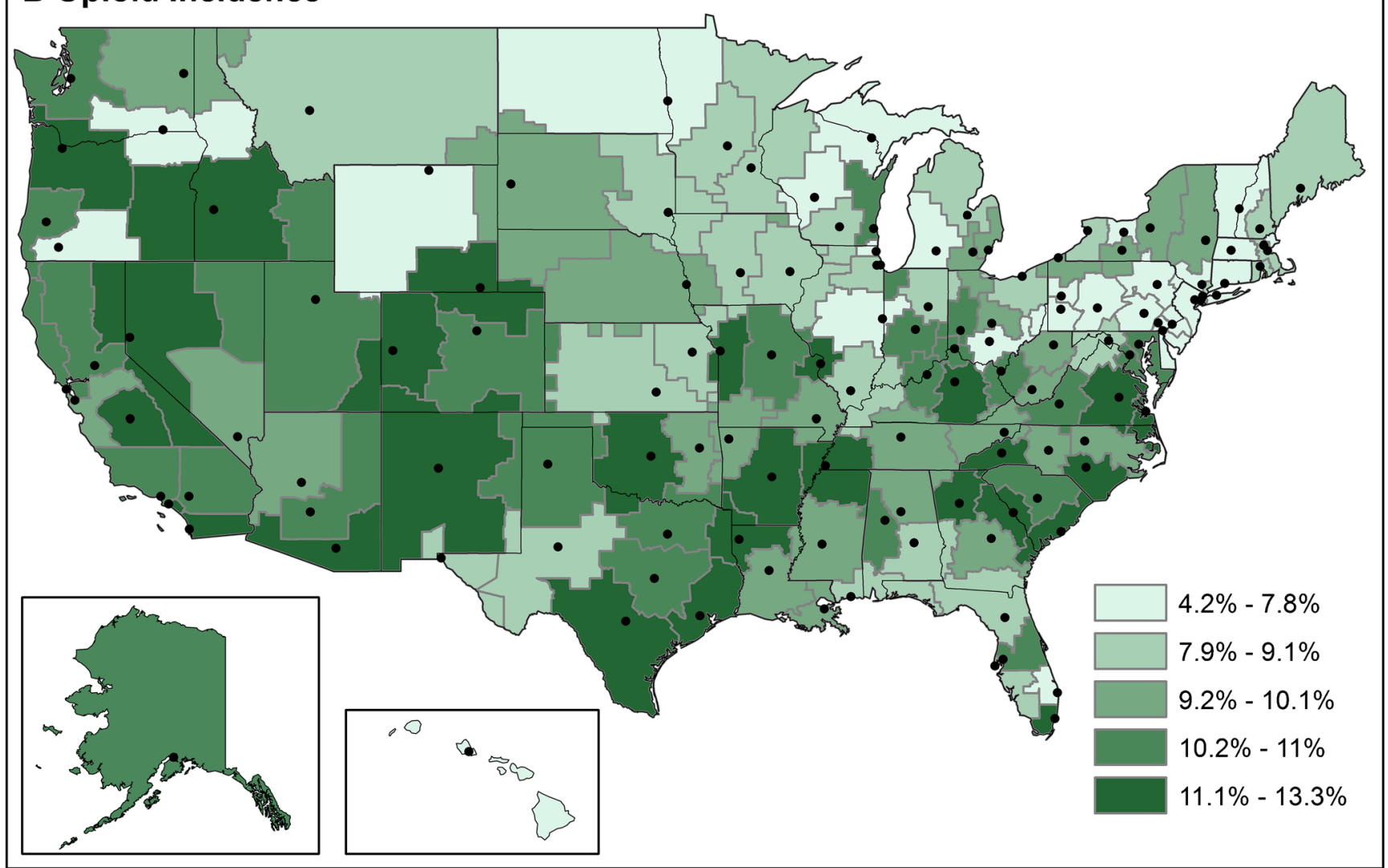

Figure 2 Opioid Prescribing Prevalence (a) and Incidence (b) in FY2012, in Quintiles. Opioid prescribing prevalence was defined as at least one opioid prescription during FY2012. Opioid prescribing incidence was defined as a first opioid prescription during FY2012, preceded by a oneyear (365 day) period with no opioid prescribed. 
Table 2 Variation in Mean Facility Prevalence Per Facility Groupings Based on Change in Incident Prescribing ${ }^{1}$

\begin{tabular}{|c|c|c|c|c|c|}
\hline & \multirow[b]{2}{*}{$\begin{array}{l}\text { All } \\
\mathbf{N}=137\end{array}$} & \multicolumn{4}{|c|}{ Incident Prescribing Change Group (in terms of absolute \%) } \\
\hline & & $\begin{array}{l}>0.5 \% \text { decrease } \\
\mathrm{N}=33\end{array}$ & $\begin{array}{l}\text { No change } \\
N=28\end{array}$ & $\begin{array}{l}0.5-1.5 \% \text { increase } \\
\mathrm{N}=31\end{array}$ & $\underset{\mathrm{N}=45}{\geq 1.5 \% \text { increase }}$ \\
\hline FY04 prevalence & 19.0 & 25.4 & 22.5 & 18.1 & 12.8 \\
\hline FY12 prevalence & 33.0 & 39.3 & 35.9 & 31.6 & 27.4 \\
\hline Absolute change & 14.0 & 13.9 & 13.4 & 13.5 & 14.6 \\
\hline Relative change & $74 \%$ & $55 \%$ & $60 \%$ & $75 \%$ & $114 \%$ \\
\hline
\end{tabular}

FY=Fiscal Year

${ }^{1}$ Incident prescribing is defined as a new opioid prescription provided to a veteran who had not received an opioid prescription in the preceding 365 days. The change in incident prescribing is the absolute percentage change in facility-level incidence rates between FY2004 and FY2012.

\section{DISCUSSION}

The percentage of veterans with prevalent opioid receipt increased substantially, from $18.9 \%$ to $33.4 \%$, over the nine years of observation. This increase was accompanied by a comparatively stable percentage of incident opioid recipients, at $8.8 \%$ in FY2004, peaking at $10.2 \%$ in FY2011, and most recently, at $9.8 \%$ in FY2012. The rates we found in a veteran population not defined by chronic pain can be contextualized by studies in a $5 \%$ sample in VHA that saw an increase in annual-period prevalence from $17.4 \%$ to $24.1 \%$ between FY2001 and FY2009, ${ }^{3}$ in a national sample of veterans with chronic non-cancer pain reporting that $50 \%$ received opioids in $2011,{ }^{22}$ and in a sample of disabled Medicare beneficiaries under 65 years of age with a $43.7 \%$ rate of any opioid use and $23.1 \%$ rate of chronic use in $2011 .^{23}$

Facilities with the highest prevalence of opioid prescribing in FY2004 tended to have declining rates of incident prescribing over the time period measured. This finding suggests the possibility of a saturation effect: as prevalent prescribing increases, fewer unexposed patients are available for incident prescription. While not all prevalent prescribing in our study constitutes long-term use, as defined elsewhere, ${ }^{24}$ Edlund et al. ${ }^{22}$ found that the majority of veterans with chronic noncancer pain receiving opioids had over 90 days prescribed per year. Rates of long-term opioid use in two large health plans increased substantially from 1997 to $2005,{ }^{25}$ suggesting that trends outside VHA parallel our observations.

The reasons for both the increase and the regional variation in prevalent opioid receipt are unclear. Chronic pain diagnoses may be increasing, ${ }^{26,27}$ possibly related to changing rates of obesity, depression, public awareness, and medicalization, among other factors. ${ }^{26}$ Women and veterans of both sexes with polytrauma and traumatic brain injury are increasingly seeking care. While chronic pain is more common in women ${ }^{28}$ and often accompanies other sequelae of trauma, ${ }^{29}$ it is unclear whether demographic changes alone explain the dramatic national increases and wide variation across regions or facilities. Recent studies have found relatively stable proportions with regard to pain experienced among veterans of Operation Iraqi Freedom (OIF), Operation Enduring Freedom (OEF), and Operation New Dawn (OND), ${ }^{30}$ as well as reduced odds for high-volume opioid receipt in OIF/OEF veterans. ${ }^{22}$ It is not possible to determine whether increased opioid use results from a greater prevalence or recognition of chronic pain, is driven by the same forces that drive increases in chronic pain condition diagnoses, or itself contributes to pain chronicity or chronic pain reporting.

Comparisons between rates of prevalent and incident opioid receipt provide important new insight into the factors accounting for growth in opioid prescribing. The only group that experienced increased incident rates was that of veterans aged 65-79 years. This increase may reflect greater willingness on the part of patients in this age range to use these medications, or on the part of providers to prescribe them to older adults, as has been articulated in guidelines widely seen as recommending the use of opioids for older adults with persistent pain. ${ }^{31}$ However, we observed that the older age groups also had significantly lower prevalence than younger age groups in FY2004; a greater proportion of individuals did not have prior receipt of opioids, and thus could become incident recipients.

The relationship between high prevalent opioid receipt in FY2004 and low increases - or in some cases decreases - in incident opioid receipt through FY2012 is apparent within regions and by facilities grouped according to change in incidence. Higher prevalent opioid receipt was observed in the South and West as early as $1992 ;{ }^{9}$ both of these regions experienced stable or decreased incident receipt rates, albeit remaining at rates higher than those in the Northeast and Midwest. The latter regions, with lower prevalence rates, saw the largest absolute increases in incidence.

We saw wide variations in increased rates of prevalent opioid prescribing at the facility level as well as among facilities in which incident prescribing rates were steady or declined. Additional work is needed to identify whether these declines occurred passively due to saturation in areas of high prevalence, or as a result of emerging awareness of issues related to opioid safety, as reflected in both scientific ${ }^{32,33}$ and lay media, and organized efforts to reduce inappropriate prescribing. ${ }^{34-37}$ An improved understanding of temporal and regional trends and variations in opioid prescribing may further inform the design and targeting of interventions to improve opioid prescribing behavior, as well as the assessment of policy changes, such as the October 6,2014, rescheduling of hydrocodone combination products to Schedule II. 
New prescriptions or conversion to long-term opioid use are distinct aspects of the persistent growth in opioid use. The discordance we found between increases in prevalent and incident prescribing implies a saturation effect: a substantial proportion of incident recipients go on to become prevalent opioid recipients. The rate at which incident recipients - that is, new patients starting short-term courses of opioid therapy - convert to long-term receipt has not been studied directly in a general population.

Cohort studies seeking to assess incident opioid receipt often exclude prevalent recipients; high prevalent rates may mitigate the generalizability of such study results. Dobscha et $\mathrm{al}^{38}$ studied a cohort of 17,126 patients defined by persistent elevated pain, in which only 5,961 (35\%) had not received any opioid in the 12 months prior to the index date. Among the opioid-naïve patients, $13.2 \%$ (273 of 1,797) who received any opioids went on to receive long-term opioid therapy. Furthermore, other investigators have shown that over half of patients receiving 90 days of continuous opioid therapy tend to remain on opioids for many years. ${ }^{39}$ Our post hoc analysis demonstrating an increase in median calendar days of opioids received provides support for the notion of increased long-term use.

This study has a number of limitations. First, it was performed in VHA, which may limit generalizability. However, as pain management and patient safety related to opioids are high-priority areas at VHA, developing methods to assess changes in prevalence and incidence is particularly important. Second, VHA administrative pharmacy databases contain only those prescriptions written and dispensed by VHA. As it is possible that patients may have obtained opioid prescriptions from non-VA providers, our rates are likely understated. Third, we did not examine provider-level prescribing or indication for opioid use, and therefore cannot assess the degree to which individual providers or acute pain conditions may have driven the patterns we observed. Fourth, our results cannot be directly compared to prior studies estimating prevalence in cohorts defined by the presence of pain, as we did not define inclusion criteria by chronic pain or cancer diagnosis; our previous work has shown that these diagnoses correlate poorly with opioid prescribing, including long-term prescriptions. ${ }^{40}$

Finally, while our results suggest an increasing propensity for new opioid users to become chronic users, which may be a substantial driver of higher opioid prevalence, our study was not specifically designed to adequately address this issue. Future research following incident users forward through time would be needed to determine the rate of and potential risk factors for conversion of incident users to chronic long-term users.

In conclusion, our results confirm the rapid and generalized rise in opioid prescribing observed in prior studies, and extend this observation by distinguishing incident receipt as a subset of prevalent receipt. Trends demonstrating decreased incident receipt in regions with high and increasing rates of prevalence suggest that incidence and prevalence reflect distinct prescribing or use practices. In other words, low or declining incident receipt rates in the highest prevalence areas may suggest a trend towards long-term opioid therapy. Future work should aim to better understand the transition from one-time or occasional receipt to recurrent or long-term receipt. Factors driving variability in prescribing trends across facilities should likewise be investigated. Both lines of inquiry have the potential to inform clinical and systems interventions to encourage appropriate opioid use in the ambulatory setting.

ACKNOWLEDGMENTS: The work reported here was supported by the Department of Veterans Affairs, Veterans Health Administration, Office of Rural Health, Veterans Rural Health Resource Center-Central Region, and the Health Services Research and Development (HSR\&D) Service through the Comprehensive Access and Delivery Research and Evaluation (CADRE) Center (CIN 13-412; CDA 10-017).

This manuscript is not under review elsewhere, and there is no prior publication of manuscript contents. The views expressed in this article are those of the authors, and do not necessarily represent the views of the Department of Veterans Affairs. Dr. Lund had full access to all of the data in the study and takes responsibility for the integrity of the data and the accuracy of the data analysis.

Dr. Mosher was involved in the design and conduct of the study, interpretation of the data, and preparation, review, and approval of the manuscript. Dr. Krebs was involved in interpretation of the data, and review and approval of the manuscript.

Dr. Carrel was involved in analysis and interpretation of the data, preparation of figures, and review and approval of the manuscript. Dr. Kaboli was involved in the design and conduct of the study, analysis and interpretation of the data, and preparation, review, and approval of the manuscript. Dr. Vander Weg was involved in interpretation of the data, and review and approval of the manuscript. Dr. Lund was involved in the design and conduct of the study, the collection, management, analysis, and interpretation of the data, and the preparation, review, and approval of the manuscript.

Conflict of Interest: Dr. Kaboli has testified as part of an FDA advisory panel on the scheduling of hydrocodone. The remaining authors report no conflict of interest with regard to this study.

Corresponding Author: H. J. Mosher, MFA, M.D.; Iowa City VA Healthcare System, 601 Highway 6 West, Mailstop 152, Iowa City, IA 52246-2208, USA (e-mail: hilary.mosher@va.gov).

\section{REFERENCES}

1. Volkow ND, Frieden TR, Hyde PS, Cha SS. Medication-Assisted Therapies-Tackling the Opioid-Overdose Epidemic. N Engl J Med. 2014:online first April 23, 2014.

2. Alexander GC, Kruszewski SP, Webster DW. Rethinking opioid prescribing to protect patient safety and public health. JAMA. 2012;308(18):18656.

3. Bohnert AS, Ilgen MA, Trafton JA, et al. Trends and Regional Variation in Opioid Overdose Mortality Among Veterans Health Administration Patients, Fiscal Year 2001 to 2009. Clin J Pain. Nov 252013.

4. Warner MLC, Makuc DM, Anderson RN, Minino AM. Drug poisoning deaths in the United States, 1980-2008. Hyattsville, MD: US Department of Health and Human Service, CDC, National center for Health Statistics; 2011.

5. Carey B. Prescription painkillers seen as a gateway to heroin. The New York Times. February 10, 2014, 2014.

6. Catan T, Perez E. A pain-drug champion has second thoughts. The Wall Street Journal. December 17, 2012, 2012.

7. Fauber J, Fiore K. Killing pain: fewer opioid scripts. MedPage Today. 2014. http://www.medpagetoday.com/PainManagement/PainManagement/ 44499. Accessed April 30, 2014.

8. Daubresse M, Chang HY, Yu Y, et al. Ambulatory diagnosis and treatment of nonmalignant pain in the United States, 2000-2010. Med Care. 2013;51(10):870-8. 
9. Olsen Y, Daumit GL, Ford DE. Opioid prescriptions by U.S. primary care physicians from 1992 to 2001. J Pain. 2006;7(4):225-35.

10. Olfson M, Wang S, Iza M, Crystal S, Blanco C. National trends in the office-based prescription of schedule II opioids. J Clin Psychiatry. 2013;74(9):932-9.

11. Paulozzi LJ, Ryan GW. Opioid analgesics and rates of fatal drug poisoning in the United States. Am J Prev Med. 2006;31(6):506-11.

12. Sullivan MD, Edlund MJ, Fan MY, Devries A, Brennan Braden J, Martin BC. Trends in use of opioids for non-cancer pain conditions 2000-2005 in commercial and Medicaid insurance plans: the TROUP study. Pain. 2008;138(2):440-9.

13. Gellad WF, Good CB, Amuan ME, Marcum ZA, Hanlon JT, Pugh MJ. Facility-level variation in potentially inappropriate prescribing for older veterans. J Am Geriatr Soc. 2012;60(7):1222-9.

14. Franklin GM. Opioids for chronic noncancer pain: A position paper of the American Academy of Neurology. Neurology. 2014;83(14):1277-84.

15. Stein C. Opioids, sensory systems and chronic pain. Eur J Pharmacol. 2013;716(1-3): 179-87.

16. Ernst ME, Lund BC. Renewed interest in chlorthalidone: evidence from the Veterans Health Administration. J Clin Hypertens. 2010;12(12):927-34.

17. Lund BC, Charlton ME, Steinman MA, Kaboli PJ. Regional differences in prescribing quality among elder veterans and the impact of rural residence. J Rural Health Off J Am Rural Health Assoc Natl Rural Health Care Assoc. 2013;29(2):172-9.

18. Young JW, Juurlink DN. Tramadol. CMAJ. 2013;185(8):E352.

19. Giraudon I, Lowitz K, Dargan PI, Wood DM, Dart RC. Prescription Opioid Abuse in the United Kingdom. Br J Clin Pharmacol. Apr 182013.

20. Bernardy NC, Lund BC, Alexander B, Friedman MJ. Increased polysedative use in veterans with posttraumatic stress disorder. Pain Med. 2014; 15(7): 1083-90.

21. Census regions and divisions of the United States. http://www.census. gov/geo/maps-data/maps/pdfs/reference/us_regdiv.pdf. Accessed September 5, 2013, 2013.

22. Edlund MJ, Austen MA, Sullivan MD, et al. Patterns of Opioid Use for Chronic Non-Cancer Pain in the Veterans Health Administration from 2009 to 2011. Pain. Aug 292014.

23. Morden NE, Munson JC, Colla CH, et al. Prescription opioid use among disabled medicare beneficiaries: intensity, trends, and regional variation. Med Care. 2014;52(9):852-9.

24. Von Korff M, Saunders K, Thomas Ray G, et al. De facto long-term opioid therapy for noncancer pain. Clin J Pain. 2008;24(6):521-7.

25. Campbell CI, Weisner C, Leresche L, et al. Age and gender trends in longterm opioid analgesic use for noncancer pain. Am J Public Health. 2010;100(12):2541-7.
26. Freburger JK, Holmes GM, Agans RP, et al. The rising prevalence of chronic low back pain. Arch Intern Med. 2009;169(3):251-8.

27. Sinnott P, Wagner TH. Low back pain in VA users. Arch Intern Med. 2009;169(14):1338-9. author reply 1339.

28. Oliva EM, Midboe AM, Lewis ET, et al. Sex Differences in Chronic Pain Management Practices for Patients Receiving Opioids from the Veterans Health Administration. Pain Med. Jul 132014.

29. Lew HL, Otis JD, Tun C, Kerns RD, Clark ME, Cifu DX. Prevalence of chronic pain, posttraumatic stress disorder, and persistent postconcussive symptoms in OIF/OEF veterans: polytrauma clinical triad. J Rehabil Res Dev. 2009;46(6):697-702.

30. Cifu DX, Taylor BC, Carne WF, et al. Traumatic brain injury, posttraumatic stress disorder, and pain diagnoses in OIF/OEF/OND Veterans. J Rehabil Res Dev. 2013;50(9):1169-76.

31. American Geriatrics Society Panel on the Pharmacological Management of Persistent Pain in Older P. Pharmacological management of persistent pain in older persons. Pain Med. 2009;10(6):1062-83.

32. Von Korff M, Kolodny A, Deyo RA, Chou R. Long-term opioid therapy reconsidered. Ann Intern Med. 2011;155(5):325-8.

33. Sullivan MD, Ballantyne JC. What are we treating with long-term opioid therapy? Arch Intern Med. 2012;172(5):433-4.

34. Manchikanti L, Singh A. Therapeutic opioids: a ten-year perspective on the complexities and complications of the escalating use, abuse, and nonmedical use of opioids. Pain Physician. 2008;11(2 Suppl):S63-88.

35. Nelson LS, Perrone J. Curbing the opioid epidemic in the United States: the risk evaluation and mitigation strategy (REMS). JAMA. 2012;308(5):457-8.

36. Kroenke K, Krebs E, Wu J, et al. Stepped Care to Optimize Pain care Effectiveness (SCOPE) trial study design and sample characteristics. Contemp Clin Trials. 2013;34(2):270-81.

37. Garg RK, Fulton-Kehoe D, Turner JA, et al. Changes in opioid prescribing for Washington workers' compensation claimants after implementation of an opioid dosing guideline for chronic noncancer pain: 2004 to 2010. J Pain. 2013;14(12):1620-8.

38. Dobscha SK, Morasco BJ, Duckart JP, Macey T, Deyo RA. Correlates of prescription opioid initiation and long-term opioid use in veterans with persistent pain. Clin J Pain. 2013;29(2):102-8.

39. Martin BC, Fan MY, Edlund MJ, Devries A, Braden JB, Sullivan MD. Long-term chronic opioid therapy discontinuation rates from the TROUP study. J Gen Intern Med. 2011;26(12):1450-7.

40. Mosher HJ, Jiang L, Vaughan Sarrazin MS, Cram P, Kaboli PJ, Vander Weg MW. Prevalence and characteristics of hospitalized adults on chronic opioid therapy. J Hosp Med. 2014;9(2):82-7. 